\title{
EVALUATION OF A CUBIC EULER SUM
}

\author{
RAMYA DUTTA
}

Abstract. In this paper we calculate the cubic series

$$
\sum_{n=1}^{\infty}\left(\frac{H_{n}}{n}\right)^{3}
$$

and two related Euler Sums of weight 6 by a technique involving only the manipulation of series. We also provide a second approach of the computation involving special logarithmic integrals.

Mathematics subject classification (2010): 33B15, 33B30, 40B10, 40C05.

Keywords and phrases: Logarithmic integrals, harmonic numbers, Euler sums, Riemann zeta function.

\section{REFERENCES}

[1] J. M. Borwein, R. Girgensohn, Evaluation of triple Euler sums, Electron. J. Combin. (1996), $2-7$.

[2] Junesang Choi, H. M. SRivastava, Explicit evaluation of Euler and related sums, Ramanujan Journal 10 (2005), 51-70.

[3] C. MARKETt, Triple sums and the Riemann zeta function, J. Number Theory 48 (1994), 113-132.

[4] L. Tornheim, Harmonic double series, Amer. J. Math. 72 (1950), 303-314.

[5] J. G. HuARD, K. S. Williams, And N.-Y.ZHANG, On Tornheim's double series, Acta Arithmetica 75 (1996), 105-117.

[6] C. I. Valean, O. Furdui, Reviving the quadratic series of Au-Yeung, J. Classical Anal. 6 (2015), no. $2,113-118$. 